\title{
Multimodal cardiac imaging of a postinfarction subvalvular left ventricular aneurysm
}

\author{
Jan Menke, ${ }^{1}$ Carsten Oliver Sahlmann ${ }^{2}$
}

${ }^{1}$ Radiology Center, University Medical Center Goettingen, Goettingen, Germany ${ }^{2}$ Department of Nuclear Medicine, University Medical Center Goettingen, Goettingen, Germany

\section{Correspondence to}

Dr Jan Menke,

Menke-J@T-Online.de

Accepted 29 January 2015

\section{DESCRIPTION}

A 61-year-old smoking patient presented with leftsided heart failure. Chest X-ray showed cardiac calcifications. Cardiac MRI confirmed a basolateral left ventricular aneurysm, of size $4.5 \times 3.3 \mathrm{~cm}$, with turbulent flow inside (video 1). Besides a thick hypointense fibrous mural scar (figure 1, arrow), there was late gadolinium enhancement of the remaining non-contractile thinned myocardium (figure 1, arrowheads), consistent with residuals of a transmural infarction. Coronary angiography revealed proximal occlusion of the left circumflex artery. Owing to recurrent ventricular tachycardia,

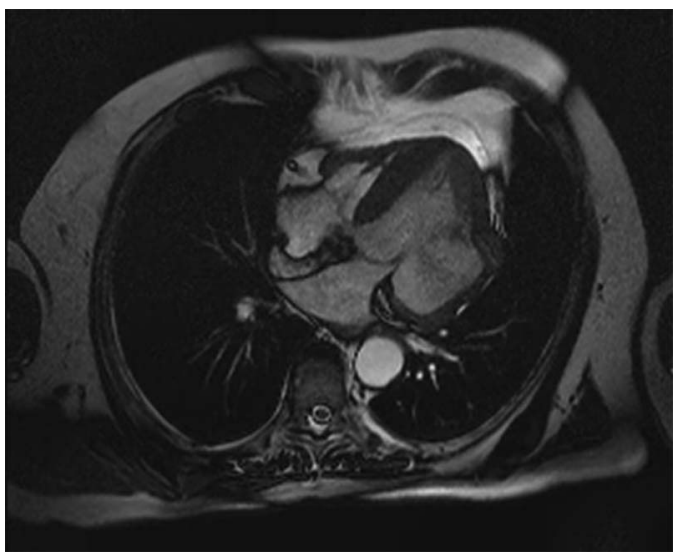

Video 1 MRI cine sequence of the four-chamber view showing the akinetic aneurysm with turbulent flow inside. The basolateral left ventricular aneurysm extended near to the mitral valve.

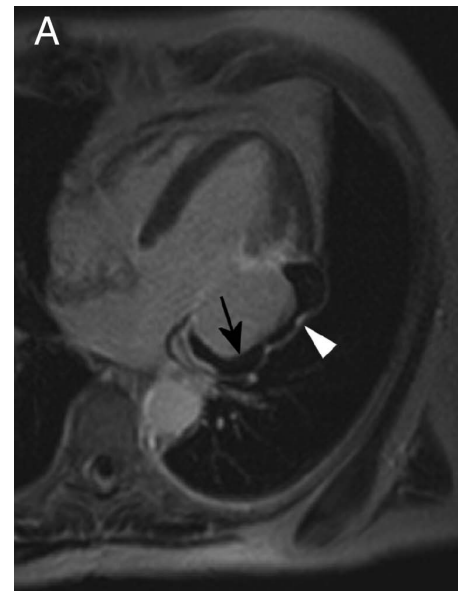

To cite: Menke J, Sahlmann CO. BMJ Case Rep Published online: [please include Day Month Year] doi:10.1136/bcr-2014208139 the patient received an implantable cardioverterdefibrillator. He decided against aneurysmectomy.

Seven years later, lung cancer was incidentally detected (figure 2, arrow). Positron emission tomography (PET) with CT $\left({ }^{18} \mathrm{~F}\right.$-fluorodeoxyglucose $\mathrm{PET} / \mathrm{CT}$ ) depicted the cancer (figure A, arrow) and indicated no metastases. The transmural infarction region showed no glucose metabolism (figure $3 \mathrm{~B}$, arrowheads) whereas the other left ventricular myocardium was viable. CT scan confirmed the aneurysm's hypodense fibrous scar (figure 3C, arrow) and the peripheral calcifications (figure 3C, arrowheads). In comparison to the previous MRI

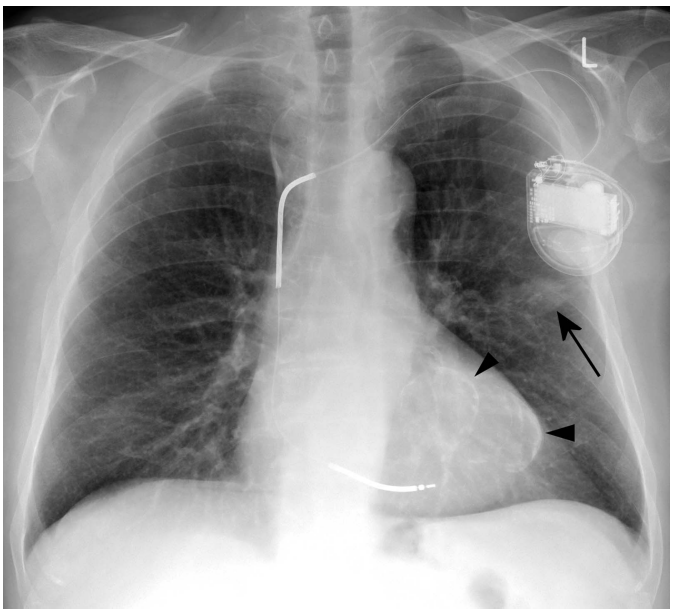

Figure 2 Chest X-ray. At follow-up the chest X-ray incidentally showed a shadowing that turned out being lung cancer (arrow). The calcifications of the left ventricular aneurysm are also visible (arrowheads).
Figure 1 Cardiac MRI. (A) Four-chamber view and (B) short-axis view of gadolinium-enhanced cardiac MRI. These images show the basal anterolateral to posterolateral left ventricular aneurysm that extended up to the mitral valve. Besides a thick hypointense fibrous mural scar (arrows) there was late gadolinium enhancement of the remaining thinned myocardium (arrowheads). 
Figure 3 Positron emission tomography (PET) with CT $\left({ }^{18} \mathrm{~F}-\mathrm{FDG}\right.$ $\mathrm{PET} / \mathrm{CT})$ showing the lung cancer ( $\mathrm{A}$, arrow) and indicated no metastases. The cardiac transmural infarction region showing no glucose metabolism at PET ( $B$, arrowheads) whereas the other left ventricular myocardium was viable ( $B$, arrow). CT confirmed the aneurysm's hypodense fibrous mural scar ( $C$, arrow) and the peripheral calcifications ( $C$, arrowheads).
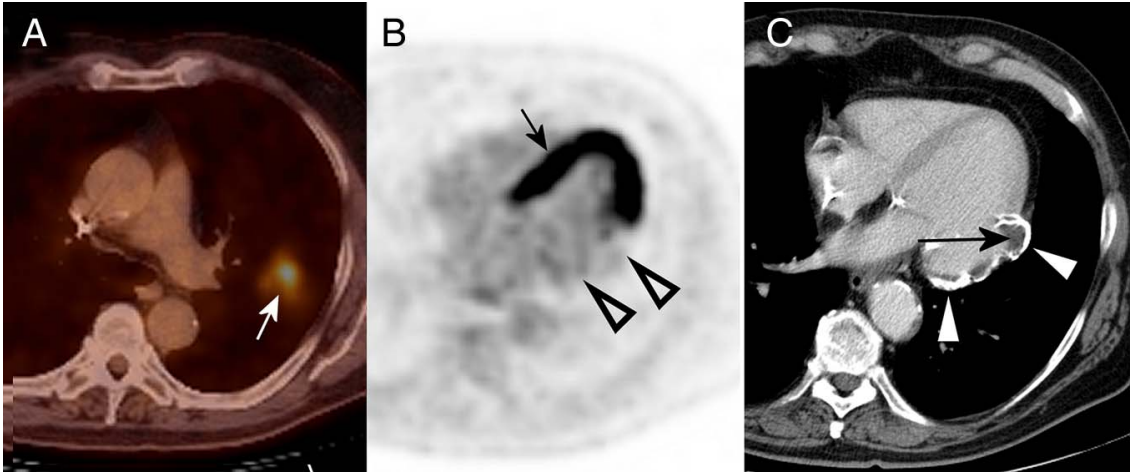

the aneurysm's size was unchanged. The lung cancer was resected and has not recurred so far.

These multimodal images show different characteristics of a left ventricular aneurysm. ${ }^{1}{ }^{2}$ About $95 \%$ of such aneurysms result from myocardial infarction. ${ }^{1}$ They mostly have an anterior/apical location, whereas the presented location is less frequent. ${ }^{34}$ If the aneurysm's wall is thin then its risk of rupture is increased. Such rapture can be prevented by surgery that may also improve cardiac function. ${ }^{5}$ The incidence of ventricular arrhythmia is increased and the aneurysm may be a source of arterial thromboembolism.

\section{Learning points}

Most cardiac ventricular aneurysms result from transmural infarction.

- Left ventricular postinfarction aneurysms have different imaging features, such as a fibrous non-vital mural scar and occasionally peripheral calcifications.

- These aneurysms have a risk to rupture and the incidence of ventricular arrhythmia is increased; these may be a source of arterial thromboembolism and can be treated by surgery that can also improve cardiac function.
In this patient, the lung cancer was not directly related to the cardiac aneurysm. However, both of the different diseases may have had smoking as the common aetiology. Possibly the smoking has caused (1) coronary artery disease with subsequent myocardial infarction and formation of the cardiac aneurysm and (2) the lung cancer that occurred several years after the cardiac aneurysm.

Contributors JM is the guarantor of the study and responsible for the overall content. JM and COS contributed to conception and design of the work, interpreted clinical data, drafted the article and revised it critically for important intellectual content, and approved the final version to be published.

Competing interests None.

Patient consent Obtained.

Provenance and peer review Not commissioned; externally peer reviewed.

\section{REFERENCES}

1 Antunes MJ, Antunes PE. Left-ventricular aneurysms: from disease to repair. Expert Rev Cardiovasc Ther 2005:3:285-94.

2 Cho MN, Mehta SK, Matulevicius S, et al. Differentiating true versus pseudo left ventricular aneurysm: a case report and review of diagnostic strategies. Cardiol Rev 2006; 14:e27-30

3 Pektok E, Cikirikcioglu M, Didier $D$, et al. Submitral left ventricular aneurysm: a rare but challenging pathology to treat. J Card Surg 2008;23:533-5.

4 Toker ME, Onk OA, Alsalehi S, et al. Posterobasal left ventricular aneurysms: surgical treatment and long-term outcomes. Tex Heart Inst J 2013;40:424-7.

5 Parolari A, Naliato M, Loardi C, et al. Surgery of left ventricular aneurysm: a meta-analysis of early outcomes following different reconstruction techniques. Ann Thorac Surg 2007;83:2009-16.

Copyright 2015 BMJ Publishing Group. All rights reserved. For permission to reuse any of this content visit http://group.bmj.com/group/rights-licensing/permissions.

BMJ Case Report Fellows may re-use this article for personal use and teaching without any further permission.

Become a Fellow of BMJ Case Reports today and you can:

- Submit as many cases as you like

- Enjoy fast sympathetic peer review and rapid publication of accepted articles

- Access all the published articles

- Re-use any of the published material for personal use and teaching without further permission

For information on Institutional Fellowships contact consortiasales@bmjgroup.com

Visit casereports.bmj.com for more articles like this and to become a Fellow 